Jurnal Akuntansi Manajemen Madani

Vol. 7, No. 1, Maret 2021

\title{
ANALISIS PENGARUH KUALITAS PELAYANAN TERHADAP KEPUASAN \\ NASABAH PT. BANK RAKYAT INDONESIA, TBK (STUDI KASUS MAHASISWA POLITEKNIK NEGERI BALIKAPAPAN)
}

\author{
Bambang Jati \\ Ida Suriana, \\ 1 Politeknik Negeri Balikpapan \\ 2 Politeknik Negeri Balikpapan \\ *ida.suriana@poltekba.ac.id
}

\begin{abstract}
Abstrak
Penelitian ini menjelaskan pengaruh kuliatas pelayanan terhadap kepuasan nasabah. Penelitian ini dirancang untuk menguji tingkat pelayanan terhadap kepuasan nasabah dan untuk mengetahui apakah kualitas pelayan berupa wujud fisik (tangibles), kehandalan (reliability), daya tanggap (responsiveness), jaminan (assurance) dan kepedulian (emphaty) berpengaruh pada kepuasan nasabah. Jumlah sampel dalam penelitian ini adalah sebanyak 194 mahasiswa dimana jumlah tersebut adalah jumlah mahasiswa yang bersedia mengisi kuesioner yang telah diberikan. Jumlah sampel tersebut dengan tingkat kesalahan 5\%. Dari hasil penelitian secara parsial terdapat dua variabel independen yang berpengaruh secara signifikan terhadap kepuasan pelanggan yaitu responsiveness dan empati.

Kata kunci : wujud fisik, kehandalan, daya tanggap, jaminan dan kepedulian.
\end{abstract}

\section{PENDAHULUAN}

Undang-undang Republik Indonesia No. 7 Tahun 1992 tentang perbankan yang telah diubah dengan undang-undang No. 10 Tahun 1998 menjelaskan Bank adalah badan usaha yang menghimpun dan dari masyarakat dalam bentuk simpanan dan menyalurkan kepda masyarakat dalam bentuk kredit dan/atau bentuk-bentuk lainya dalam rangka meningkatkan taraf hidup rakyat. Bank memiliki pernan penting untuk mendorong perekonomina bangsa, beberapa peran penting perbankan menurut Hasibuan (2015) bank sebagai pegumpul dana dari SSU(Surplus Spending Unit) dan penyalur kredit kepada DSU (Defisit Spending Unit), tempat menabung yang efektif dan produktif bagi masyarakat, pelaksana dan memperlancar lalu lintas pembayaran dengan aman, praktis dan ekonomis, sebagai penjamin penyelesaian perdagangan dengan menerbitkan L/C, sebagai penyelesaian proyek dengan menerbitkan bank garansi.

Pada era globalisasi dan era digital saat ini, persaingan dalam dunia bisnis semakin bertambah ketat. Persaingan ini menuntut para pelaku bisnis untuk mampu memaksimalkan 
kinerja perusahaannya agar dapat bersaing di pasar. Perusahan harus berusaha keras untuk dapat memahami setiap kebutuhan pelanggan agar mampu bertahan dalam persaingan usaha yang semakin ketat. Tidak terkecuali bisnis dalam jasa perbankan Dengan memahami kebutuhan, keinginan dan permintaan pelanggan, maka akan memberikan masukan penting bagi perusahaan untuk merancang strategi pemasaran agar dapat menciptakan kepuasan bagi pelanggannya (Kotler dan Armstrong, 2001).

Kepuasan sangat berarti bagi perusahaan agar mampu bertahan dalam persaingan dan menjadi bagian yang sangat penting dalam proses bisnis perbankan.Kepuassan pelanggan menjadi bagian wajib dalam setiap organisasi bisnis. Tjiptono (2012) menjelaskan manfaat dari kepuasan pelanggan diantaranya : (1) berdampak positif terhadap loyalitas pelanggan; (2) berpotensi menjadi sumber pendapatan masa depan terutama melalui pembelian ulang, crossselling dan up-selling, (3) menekan biaya transaksi pelanggan di masa depan, terutama biayabiaya komunikasi pemasaran, penjualan dan layanan pelanggan; (4) menekan volatilitas dan toleransi harga, terutama kesediaan pelanggan untuk membayar harga premium dan pelamggam cenderung tidak mudah tergoda untuk beralih pemasok, (6) menumbuhkan rekomendasi gethok tular positif; (7) pelanggan cenderung lebih reseptif terhadap product-line extensions, brand extensions dan new add-on services yang ditawarkan perusahaan; serta (8) meingkatkan bargaining power relatif perusahaan terhadap jaringan pemasok, mitra bisnis dan saluran distribusi. Penelitian ini dirancang untuk menguji tingkat pelayanan terhadap kepuasan nasabah dan untuk mengetahui apakah kualitas pelayan berupa wujud fisik (tangibles), kehandalan (reliability), daya tanggap (responsiveness), jaminan (assurance) dan kepedulian (emphaty) berpengaruh pada kepuasan nasabah.

Dalam industri jasa, pelanggan pasti berharap untuk mendapatkan pelayanan yang baik, sementara itu di pihak lain pemberi jasa juga mempunyai standar kualitas dalam memberikan jasanya. Demikian juga dalam dunia perbankan yang merupakan industri jasa, nasabah sebagai pelanggan pasti mempunyai harapan terhadap kualitas jasa tertentu yang mungkin berbeda dengan pemberi pelayanan. Persepsi konsumen terhadap kualitas pelayanan itu sendiri merupakan penilaian menyeluruh konsumen atas keunggulan suatu pelayanan (Kotler, 1997). PT Bank Rakyat Indonesia, Tbk merupakan salah satu bank BUMN terbesar di Indonesia yang juga memiliki moto "melayani dengan sepenuh hati". Bank yang sudah bediri sejak tahun 1895 ini juga melayani mahasiswa di Politeknik Negeri Balikpapan. Dengan banyaknya persaingan maka 
Bank BRI juga harus dapat memberikan kepuasan layanan kepada mahasiswa sebagai salah satu nasabah potensial yg dimiliki. Berangkat dari uraian diatas, maka dirumuskan judul penelitian adalah “: Analisis Pengaruh Kualitas Pelayanan Terhadap Kepuasan Nasabah PT. Bank Rakyat Indonesia, Tbk (Studi Kasus Mahasiswa Politeknik Negeri Balikapapan).

Pelayanan menekankan pada kepuasan konsumen yang dapat menciptakaan kesetiaan atau loyalitas kepada perusahaan yang telah memberikan kualitas layanan yang memuaskan. Mahasiswa menjadi nasabah potensial yang dapat menjadi nasabah yang tetap setia pada saaat sudah bekerja nantinya. Maka penulis merumusakan permasalahan sebagai berikut :

a. Apakah kualitas pelayanan Bank BRI pada mahasiswa Politeknik Negeri Balikpapan berupa wujud fisik (tangibles) mempengaruhi kepuasan pelanggan?

b. Apakah kualitas pelayanan kualitas pelayanan Bank BRI pada mahasiswa Politeknik Negeri Balikpapan berupa kehandalan (reliability) mempengaruhi kepuasan pelanggan?

c. Apakah kualitas pelayanan Bank BRI pada mahasiswa Politeknik Negeri Balikpapan berupa daya tanggap (responsiveness) mempengaruhi kepuasan pelanggan?

d. Apakah kualitas pelayanan Bank BRI pada mahasiswa Politeknik Negeri Balikpapan berupa jaminan (assurance) mempengaruhi kepuasan pelanggan?

e. Apakah kualitas pelayanan pelayanan Bank BRI pada mahasiswa Politeknik Negeri Balikpapan berupa berupa kepedulian (emphaty) mempengaruhi kepuasan pelanggan?

Untuk menghindari terjadinya perluasan ruang lingkup permasalahan maka perlu diketahui batasan masalah dari penelitian yang sedang dilakukan. Adapun batasan masalahnya adalah sebagai berikut:

a. Lingkup wailayah penelitian adalah Politeknik Negeri Balikpapan

b. Penelitian dilakukan terhadap mahasiswa Program angkatan 2017 -2020

\section{METODOLOGI PENELITIAN}

\section{Populasi dan Sampel}

Populasi dalam penelitian ini adalah mahasiswa aktif Politeknik Negeri Balikapan Jurusan angkatan 2017-2020. Jumlah Populasi Mahasiswa sebanyak 1300 mahasiswa 
Jumlah sampel dalam penelitian ini adalah sebanyak 194 mahasiswa dimana jumlah tersebut adalah jumlah mahasiswa yang bersedia mengisi kuesioner yang telah diberikan. Jumlah sampel tersebut dengan tingkat kesalahan 5\% yang diambil dalam tabel penentuan sampel dari populasi tertentu milik Sugiyono (2014).

\section{Variabel Penelitian dan Kerangka Konseptual}

1. Variabel Penelitian

Variabel dalam penelitian ini dibagi menjadi dua yaitu sebagai berikut:

a. Variabel independen

Variabel independen dalam penelitian ini adalah bukti langsung, keandalan, daya tanggap, jaminan, dan empati.

b. Variabel dependen

Variabel dependen dalam penelitian ini adalah kepuasan nasabah

2. Kerangka Konseptual

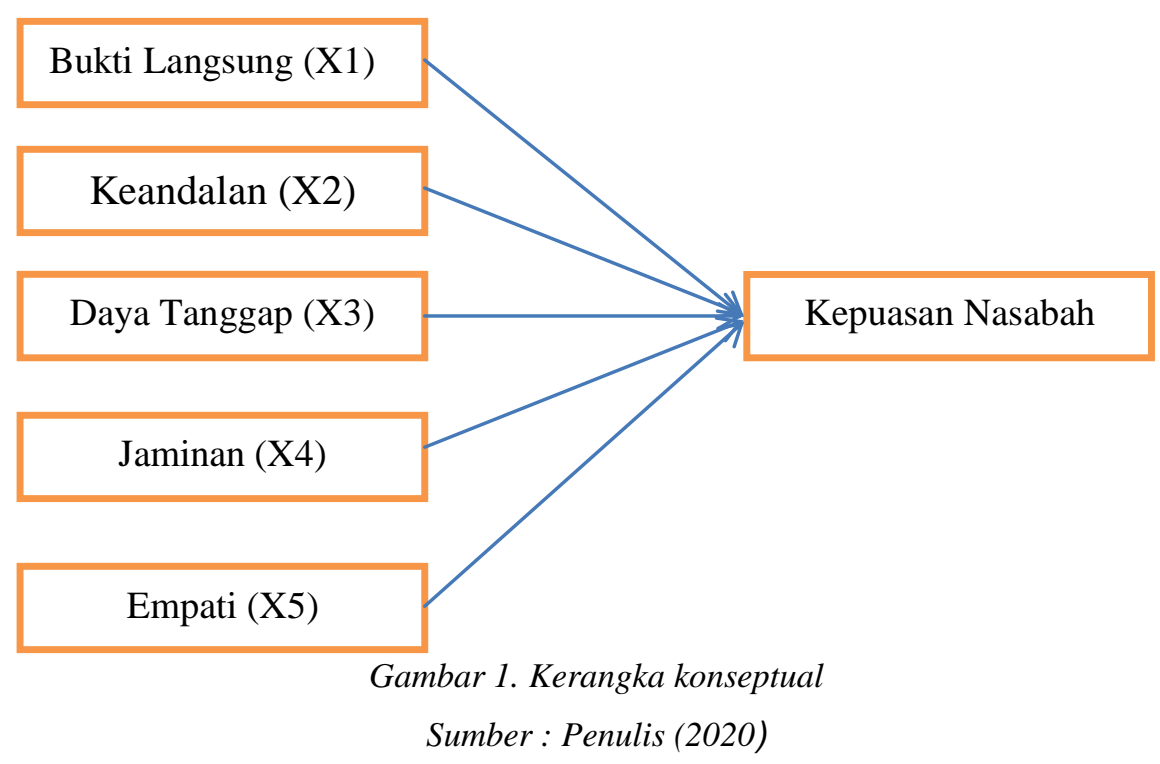

\section{HASIL DAN PEMBAHASAN}

Uji Validitas Dan Reliabilitas 
Uji Validitas Untuk mendukung analisis regresi dilakukan uji validitas dan reabilitas. Uji validitas dalam penelitian ini digunakan untuk menguji kevalidan kuesioner. Validitas menunjukkan sejauh mana ketetapan dan kecermatan suatu alat ukur dalam melakukan kecermatan fungsi alat ukurnya. Uji Validitas menggunakan KMO and Bartlett's Test dengan nilai signifkansi 0.00 yang berarti tidak ada korelasi antar variabel. Hasil Uji Realibiltas dapat dilihat dibawah ini :

Tabel 2. Hasil Uji Realibilitas

\begin{tabular}{ccc}
\hline Variabel & Cronbach's Alpha & Keterangan \\
\hline X1 & 0.896 & Reliable \\
X2 & 0.806 & Reliable \\
X3 & 0.858 & Reliable \\
X4 & 0.832 & Reliable \\
X5 & 0.867 & Reliable \\
Y & 0.854 & Reliable \\
\hline
\end{tabular}

Sumber : Data diolah (2020)

Tabel 3. Hasil Uji Validitas

KMO and Bartlett's Test

\begin{tabular}{|ll|r|}
\hline \multicolumn{2}{|c|}{ Kaiser-Meyer-Olkin Measure of Sampling Adequacy. } & .933 \\
& Approx. Chi-Square & 3112.808 \\
Bartlett's Test of Sphericity & $\mathrm{df}$ & 171 \\
& Sig. & .000 \\
\hline
\end{tabular}

\section{Uji Asumsi Klasik}

Uji asumsi klasik digunakan untuk mengetahui apakah model regresi berganda yang digunakan untuk menganalisis dalampenelitian asumsi klasik atau tidak.

a. uji normalitas

uji normalitas bertujuan untuk menguji apakh dalam model regresi, variabel penggangu atau residual memiliki distribusi normal. Dalam penelitian ini hasil uji normalitas berdistribus normal.

b. uji multikolineritas 
uji multikolineritas bertujuan untuk menguji apakah model regresi ditemukan adanya korelasi antar variable bebas (independen) (Ghozali;2009). Dalam penelitian ini tidak terjadi multikolinearitas dilihat dari nilai VIF setiap variable $<10$.

c. uji Heteroskedastisitas

uji heteroskedastisitas bertujuan menguji apakah dalam model regresi terjadi ketidaksamaan variance dari residual satu pengamatan ke pengamatan lain. (Sugiyono;2009). Hasil dari penelitian ini tidak terdapat gejala Heteroskedastisitas

\section{Analisis Regresi Berganda}

Pengujian hipotesis pada penelitian ini mengunakan analisis regresi berganda. Analisis regresi berganda digunakan untuk melihat nilai pengaruh dua atau lebih varibel bebas terhadap variabel terikat. Adapun model regresi berganda dalam penelitian ini adalah sebagai berikut : Hasil dari analisis regresi berganda dalam penelitian ini adalah sebagai berikut:

$$
\mathrm{Y}=0.400-0.14 \mathrm{X}_{1}+0.162 \mathrm{X}_{2}+0.188 \mathrm{X}_{3}-0.045 \mathrm{X}_{4}+0.660 \mathrm{X}_{5}
$$

Nilai konstanta 0.400 berarti ketika variabel tangibles, reliability, responsiveness, assurance, emphaty dianggap konstan atau tidak ada perubahan maka besarnya variabel kepuasan pelanggan adalah sebesar 0.400 satuan. Nilai $b_{1}$ sebesar 0.14 artinya jika variabel ini naik satu satuan maka variabel tangibles akan turun sebesar 0.14 satuan dengan asumsi variabel lain dianggap konstan. Nilai $b_{2}$ sebesar 0.162 artinya jika variabel ini naik satu satuan maka variabel reliability akan meningkat sebesar 0.162 dengan asumsi variabel lain dianggap konstan. Nilai $b_{3}$ sebesar 0.188 artinya jika variabel ini naik satu satuan maka variabel responsiveness akan meningkat sebesar 0.188 dengan asumsi variabel lain dianggap konstan. Nilai $\mathrm{b}_{4}$ sebesar 0.045 artinya jika variabel ini naik satu satuan maka variabel assurance akan turun sebesar 0.045 dengan asumsi variabel lain dianggap konstan. Nilai $b_{5}$ sebesar 0.660 artinya jika variabel ini naik satu satuan maka variabel emphaty akan meningkat sebesar 0.660 dengan asumsi variabel lain dianggap konstan.

\section{a. Koefisien Determinasi $\left(\mathbf{R}^{2}\right)$}

Uji ini digunakan untuk mengetahui seberapa besar presentase sumbangan pengaruh variebel independen yang terdiri tangibles, reliability, responsiveness, assurance dan emphaty terhadap kepuasan nasabah . Berdasarkan nilai Adjusted $R$ Square menunjukan angka 0.668 yang berarti $66.80 \%$ dari nilai kualitas pelayanan terhadap kepuasan nasabah ditentukan oleh variabel 
independen yang terdiri dari tangibles, reliability, responsiveness, assurance dan emphaty dan sisanya 33.20\% dipengaruhi oleh variabel lain diluar model penelitian ini.

\section{b. Uji F}

Berdasarkan hasil uji $\mathrm{F}$ didapatkan nilai signifikansi sebesar 0.000 dengan nilai $\mathrm{F}$ hitung sebesar 78.121 hal ini berarti adanya pengaruh signifikan antara variabel independen yang terdiri dari tangibles, reliability, responsiveness, assurance dan emphaty terhadap variabel dependen yaitu kepuasan nasabah.

\section{c. Uji t}

Tabel 2. Hasil Uji t

\begin{tabular}{crcc}
\hline Model & $\mathbf{B}$ & $\mathbf{t}$ & Sig \\
\hline Constanta & .400 & .599 & 0.550 \\
$\mathrm{X}_{1}$ & -0.14 & -0.224 & 0.823 \\
$\mathrm{X}_{2}$ & 0.162 & 1.832 & 0.068 \\
$\mathrm{X}_{3}$ & 0.188 & 2.170 & 0.031 \\
$\mathrm{X}_{4}$ & -0.045 & -0.481 & 0.631 \\
$\mathrm{X}_{5}$ & 0.660 & 8.697 & 0.000 \\
\hline
\end{tabular}

Sumber : Data diolah (2019)

Berdasarkan hasil regresi menggunakan SPSS 20 dapat diambil kesimpulan bahwa terdapat dua variabel independen yang berpengaruh secara signifikan terhadap kepuasan pelanggan yaitu responsiveness dan empati.

\section{KESIMPULAN DAN SARAN}

\section{Kesimpulan}

Dari hasil pembahasan yang sudah ada maka dapat ditarik kesimpulan bahwa secara simultan variabel kualitas pelayanan berpengaruh secara simultan terhadap kepuasan nasabah. Dari hasil penelitian ini agara dapat mendorong Bank BRI untuk dapat meingkatakan kualitas pelayanan yang diberikan bagi nasabah-nasabh potensial seperti mahasiswa agar dikemudiaan hari, ketika mahasiswa sudah mulai bekerja akan tetap menjadi nasabah yang setia menggunakan produkproduk yang dikeluarkan oleh bank BRI. Hal ini sesuai dengan penelitan yang dilakukan oleh 
Ahmaddien (2016). Dari lima variabel independen terdapat dua variabel yang berpengaruh secara parsial terhadap kepuasan nasabah yaitu responsiveness (daya tanggap) dan emphaty (kepedulian).

\section{Saran}

Diperlukan adanya penelitian lebih lanjut tentang kualitas pelayanan dari faktor lain selain lima faktor lain yang sudah diteliti

\section{Ucapan Terimakasih}

Penelitian ini didanai oleh DIPA Poltekba Tahun Anggaran 2020. Terimakasih kami sampaikan kepada Pusat Penelitian dan Pengabdian kepada Masyarakat Politeknik Negeri Balikpapan atas dukungan dana yang diberikan sehingga penelitian ini bisa terlaksana

\section{DAFTAR PUSTAKA}

Hasibuan Malayu S.P (2015). Dasar-Dasar Perbankan. Bumi Aksara. Jakarta

Sangadji, Etta Mamang (2013). Perilaku Konsumen. Penerbit Andi. Yogyakarta.

Kotler, Philip. (2006). Manajemen Pemasaran. Indeks. Jakarta

Laksana, Fajar (2008). Manajemen Pemasaran : Pendekatan Praktis. Graha Ilmu. Yogyakarta

Lupiyoadi, Rambat. Manajemen Pemasaran Jasa Berbasis Kompetensi. 2014. Jakarta. Penerbit Salemba Empat

Sugiyono, (2010)Metode Penelitian Bisnis. Alfabeta. Bandung.

Tjiptono.(2012) . Service Management. Penerbit Andi. Yogyakarta 